\title{
Guideline Conformity Treatment in Young Women with Early-Onset Breast Cancer in Germany
}

\author{
Telja Pursche $^{a}$ Marianne Hedderich ${ }^{a}$ Alessa Heinrichs ${ }^{a}$ Kristin Baumann ${ }^{a}$ \\ Constanze Banz-Jansen ${ }^{a}$ Achim Rody ${ }^{a}$ Annika Waldmann ${ }^{b}$ Dorothea Fischer $^{a}$ \\ a Department of Obstetrics and Gynecology, University Hospital of Schleswig-Holstein, Campus Luebeck, Germany \\ ${ }^{\mathrm{b}}$ Institute of Social Medicine and Epidemiology, University of Luebeck, Germany
}

\section{Keywords}

Breast cancer · Guideline · Therapy ·

Recommendations · Young

\section{Summary}

Background: The purpose of the study was to characterize the treatment of young mothers with breast cancer in Germany and to investigate whether it followed applicable guidelines. Method: Retrospective data obtained between 2002 and 2011 for 1,053 mothers with children of $<12$ years of age with adjuvantly treated loco-regional primary breast cancer were analyzed. Collected data included sociodemographic data, TNM stage, biology of tumor and therapies. Actually received therapies were compared to those suggested in guideline treatment plans. Results: The mean age of the patients was 39 years. $97 \%$ of the women with node positivity received an axillary dissection. Overall, $90 \%$ of the patients received chemotherapy with a guideline adherence range of $87-99 \%$ depending on clinical parameters. For radiation therapy, guideline adherence was high (range $82-100 \%$ ). $95 \%$ of the patients with a hormone receptorpositive tumor received endocrine therapy; in 94\%, tamoxifen therapy was performed in compliance with guidelines, whereas gonadotropin-releasing hormone $(\mathrm{GnRH})$ agonist therapy complied with the guidelines in $52 \%$ of the cases. Conclusion: Guideline adherence in young mothers with breast cancer in Germany was high (with the exception of $\mathrm{GnRH}$ therapy), as comorbidity or the ambiguity of the therapeutic success does not need to be considered as much in this young, otherwise usually healthy, cohort compared to an age-heterogeneous group.

\section{Introduction}

Breast cancer $(\mathrm{BC})$ remains the most frequent carcinoma in women, with an incidence of $\sim 72,000$ new cases per year occurring in Germany. Statistically, every 8th woman will contract breast cancer during her lifetime. In young women it is the most common cause of death. About every 10th woman diagnosed with BC in Germany is younger than 45 years [1]. Younger women are often affected by a more aggressive form of this disease $[2,3]$. When treating this young population, special factors have to be taken into consideration: long recurrence-free survival (RS) and overall survival (OS) have to be weighed against quality of life and reintegration into family and work life. Therefore, young patients are potentially at risk for either undertreatment, as an assumed actual protection, or overtreatment while trying to achieve maximum benefit in the long term [4].

Guidelines are based on the best available scientific evidence and clinical experience. They include systematically developed statements to assist practitioner and patient decisions about appropriate health care for specific clinical circumstances [5]. Because of different health care systems and thus different access to health care, national guidelines are needed. Wolters et al. [6] established that the recommended treatments within international guidelines are virtually identical, differing only marginally in adjuvant endocrine therapy. In Germany, the 'Arbeitsgemeinschaft Gynäkologische Onkologie' (AGO) releases annual recommendations reflecting upto-date research findings [7]. According to national consensuses, the AGO guidelines for treatment are, in fact, most frequently followed for BC therapy in Germany as they do incorporate the newest advances. Recently, international experts worked out a recommendation specifically referring to the management of young patients with breast cancer. This recommendation matches with those from the AGO but points out

\section{KARGER \\ Fax +497614520714 \\ Information@Karger.com}

www.karger.com (c) 2014 S. Karger GmbH, Freiburs

$1661-3791 / 14 / 0095-0349 \$ 39.50 / 0$

Accessible online at:

www.karger.com/brc 
essential and important aspects for young patients in more detail [8]. The BRENDA trial - a German retrospective multicenter cohort study including 9,156 patients with primary breast cancer recruited from 1992 to 2008 - examined the influence of therapy in adherence to guidelines (following the German S3 guideline) on RS and OS, and showed that guideline-consistent therapy improves RS and OS $[9,10]$. To determine whether young patients in Germany were treated in accordance with applicable AGO guidelines, we evaluated the data of 1,053 women who participated in an in-patient rehabilitation mother-child program in Germany between 2007 and 2011 and, further, compared the treatment of young mothers with data of the OVIS (oncological treatment of tumor patients in Schleswig-Holstein) study, a mixed-age collective.

\section{Material and Methods}

\section{Study Population and Data Collection}

In this retrospective clinical cohort study we analyzed data from 1,053 patients from all over Germany with an adjuvantly treated loco-regional primary breast cancer who stayed in 'Klinik Ostseedeich' in Groemitz (Germany) for in-patient rehabilitation between February 2007 and September 2008 (young mothers I, 535 patients) or between October 2010 and November 2011 (young mothers II, 518 patients). Of the 1,053 patients, $58.4 \%$ were younger than 40 years, $24.1 \%$ were younger than 35 years. All patients had at least 1 child of $<12$ years of age. Data included age of patient, number of children, date of diagnosis, place of residence, TNM-stage, tumor biology and treatment. The program was over seen by gynecologists from the Department of Gynecology and Obstetrics of the University of Schleswig-Holstein, Campus Lübeck. The study protocol was approved by the local ethics committee.

\section{Comparison Population}

The OVIS study evaluated the oncological health care of 1,927 patients who were diagnosed with primary breast cancer in Schleswig-Holstein between 2002 and 2004. As patients were recruited via the epidemiological cancer registry of Schleswig-Holstein, the study can be regarded as population based. A responder/non-responder comparison showed that participating women were representative for all breast cancer patients in Schleswig-Holstein [11, 12]. Physicians provided additional data on treatment for a subgroup of 1,141 patients. These women are comparable to the total OVIS cohort with regard to TNM, age at diagnosis, and treatment (as reported by patients) and were used in the present analysis.

\section{Evaluating Guideline Adherence}

To analyze guideline adherence, we designed treatment plans for each patient in accordance with the guidelines considering tumor stage and biology by following the AGO recommendations, and compared these plans to the actual therapy each patient had received.

\section{Statistical Analysis}

Our aim was to characterize the BC treatment of young mothers. We compared the results between cohorts I and II of young mothers, and further compared these with data from the OVIS study in a descriptive manner. In the literature, 'young BC patients' are defined as having a maximum age of 40 years at time breast cancer diagnosis. We therefore additionally divided the complete cohort of young mothers with respect to age ( $\leq 40$ and $>40$ years) and re-analyzed the results; OVIS patients were subclassified accordingly.
Qualitative data are described using relative frequencies; quantitative data are described using means, standard deviations, and ranges. Data were analyzed using SPSS (IBM SPSS 19, SPSS Corporation).

\section{Results}

The diagnosis of cancer for this cohort of young mothers was made between 2002 and 2011. The average age of the patients in Young mothers group was 39.2 years (range 21-56 years). $58.4 \%$ of these women were younger than 40 years, and $24.1 \%$ were younger than 35 years. The OVIS patients were approximately 20 years older at time of breast cancer diagnosis, with only $76(6.7 \%)$ being $\leq 40$ years and 19 $(1.7 \%)$ being $\leq 35$ years. Table 1 shows the distribution of tumor categories, nodal status, grading and receptor status. The young mother cohorts showed more pT3 tumors compared to the OVIS cohort (5.9\% vs. $4.7 \%)$ and fewer pT1 and pT4 tumors $(48.7 \%$ and $1.6 \%$ vs. $55.4 \%$ vs. $2.9 \%)$ ). The young mother cohort also showed less pN0 (53.8\% vs. $60.9 \%)$ and more pN2/ $\mathrm{N} 3$ status $(10.3 \% / 5.2 \%$ vs. $3.0 \%)$. A negative hormone receptor status was also more frequently significant $(31.6 \%$ vs. $16.7 \%$ ). Patients of $<40$ years of age, compared to those older than 40 years, showed fewer G2 tumors (young mothers $41.1 \%$ vs. $54.3 \%$; OVIS $23.7 \%$ vs. $47.3 \%$ ) and more G3 tumors (young mothers $51.1 \%$ vs. $35.6 \%$; OVIS $72.4 \%$ vs. $47.2 \%$ ). Table 2 describes the frequency of surgery and systemic therapies. With the exception of axillary surgery and gonadotropin-releasing hormone $(\mathrm{GnRH})$ treatment, no relevant difference were seen between the cohorts I and II of young mothers. There was fewer sentinel lymph node biopsies (SLNBs) and SLNBs followed by axillary dissection (AD) in young mothers in group I than in II $(24.5 \%$ and $16.8 \%$ vs. $47.5 \%$ and $24.7 \%)$ and more GnRH treatment $(\leq 40$ years $72.6 \%$ vs. $62.7 \%$ and $>40$ years $36.6 \%$ vs. $11.4 \%$ ). All together, the young mothers cohorts received more chemotherapy ( $88.9 \%$ vs. $83.4 \%$ ), while OVIS patients seemed to receive more radiation therapy and breastconserving therapy (BCT). In the young mother cohorts, patients younger than 40 years were more likely to receive AD (46.7\% vs. $34.5 \%)$, chemotherapy (93.3\% vs. $82.6 \%)$ and a taxane $(53.3 \%$ vs. $32.3 \%)$, even if they had an N0 status, compared to those older than 40 years. Figure 1 shows guideline conformity of various therapeutic parameters. All parameters show a high rate of guideline adherence in chemotherapy (range $87.0-99.0 \%$ ) and radiation (range $80.2-100 \%$ ). For endocrine therapy, we found a difference between tamoxifen therapy with a guideline conformity of $94.3 \%$ and GnRH analogues with a conformity of only $47.6 \%$.

\section{Discussion}

Only a relatively small number of patients are younger than 40 years at $\mathrm{BC}$ diagnosis. Although these patients are of 
Table 1. Tumor characteristics of the cohorts of young mothers (Young mothers I/II and all young mothers $\leq 40 />40$ years) compared to the OVIS cohort (age-heterogeneous, grouped as $40 />40$ years)

\begin{tabular}{|c|c|c|c|c|c|c|}
\hline \multirow{3}{*}{ Time period } & \multirow{3}{*}{$\begin{array}{l}\text { Young mothers I } \\
\text { 2002-2006 }\end{array}$} & \multirow{3}{*}{$\begin{array}{l}\text { Young mothers II } \\
\text { 2008-2011 }\end{array}$} & \multicolumn{2}{|c|}{ Young mothers I + II } & \multicolumn{2}{|l|}{ OVIS } \\
\hline & & & \multicolumn{2}{|l|}{ 2002-2011 } & \multicolumn{2}{|l|}{ 2001-2004 } \\
\hline & & & $\leq 40$ years & $>40$ years & $\leq 40$ years & $>40$ years \\
\hline $\mathrm{n}$ & 535 & 518 & 615 & 438 & 76 & 1,065 \\
\hline Age, years & $39.2 \pm 4.92$ & $40 \pm 5.54$ & $34.8 \pm 3.12$ & $43.2 \pm 3.23$ & $36.8 \pm 3.1$ & $60.4 \pm 10.0$ \\
\hline$\leq 35$ years, $\mathrm{n}(\%)$ & $138(25.8)$ & $116(22.4)$ & $254(24.1)$ & - & $19(1.7)$ & - \\
\hline$\leq 40$ years, $\mathrm{n}(\%)$ & $345(64.5)$ & $270(52.1)$ & $615(100)$ & - & $76(100)$ & \\
\hline \multicolumn{7}{|l|}{ Tumor size, \% } \\
\hline урт0 & 1.7 & 2.7 & 2.8 & 1.4 & - & - \\
\hline pTis & 4.9 & 3.3 & 4.2 & 3.9 & - & - \\
\hline pT1 & 46.0 & 51.5 & 48.6 & 48.9 & 55.3 & 55.5 \\
\hline pT2 & 37.6 & 36.9 & 36.4 & 38.4 & 35.5 & 35.5 \\
\hline pT3 & 7.3 & 4.4 & 5.7 & 6.2 & 3.9 & 4.8 \\
\hline pT4 & 1.9 & 1.2 & 1.6 & 1.4 & 3.9 & 2.8 \\
\hline $\mathrm{Tx}$ & 0.7 & 0.0 & 0.7 & 0 & 1.3 & 1.4 \\
\hline \multicolumn{7}{|c|}{ Axillary lymph node status, \% } \\
\hline N0 & 49.5 & 58.1 & 54.3 & 53.0 & 48.7 & 61.7 \\
\hline N1 & 31.4 & 28.4 & 29.6 & 30.4 & 47.4 & 31.3 \\
\hline $\mathrm{N} 2$ & 11.6 & 8.9 & 9.8 & 11.0 & 2.6 & 3.0 \\
\hline N3 & 5.8 & 4.6 & 5.2 & 5.3 & - & - \\
\hline $\mathrm{pNx}$ & 1.5 & 0.0 & 1.0 & 0.5 & 1.3 & 4.0 \\
\hline \multicolumn{7}{|l|}{ Grading, \% } \\
\hline G1 & 4.9 & 5.6 & 4.2 & 6.6 & 1.3 & 2.1 \\
\hline $\mathrm{G} 2$ & 45.8 & 47.5 & 41.1 & 54.3 & 23.7 & 47.3 \\
\hline G3 & 43.6 & 45.8 & 51.1 & 35.6 & 72.4 & 47.2 \\
\hline Gx & 5.8 & 1.2 & 3.6 & 3.4 & 2.6 & 3.0 \\
\hline \multicolumn{7}{|c|}{ Hormone receptor status, \% } \\
\hline Positive & 67.5 & 69.3 & 62.6 & 76.5 & 76.5 & 83.8 \\
\hline Negative & 32.5 & 30.7 & 37.4 & 23.5 & 23.5 & 16.2 \\
\hline \multicolumn{7}{|l|}{ Her 2 status, \% } \\
\hline Positive & 26.2 & 21.8 & 27.3 & 19.4 & n.a. & n.a. \\
\hline Negative & 72.7 & 78.2 & 72.0 & 80.1 & n.a. & n.a. \\
\hline Triple negative, \% & 21.3 & 24.5 & 26.8 & 17.4 & n.a. & n.a. \\
\hline
\end{tabular}

Fig. 1. Guideline conformity of therapy of the cohorts of young mothers (Young mothers I, II and all Young mothers $\leq 40$ years) and the OVIS cohort.

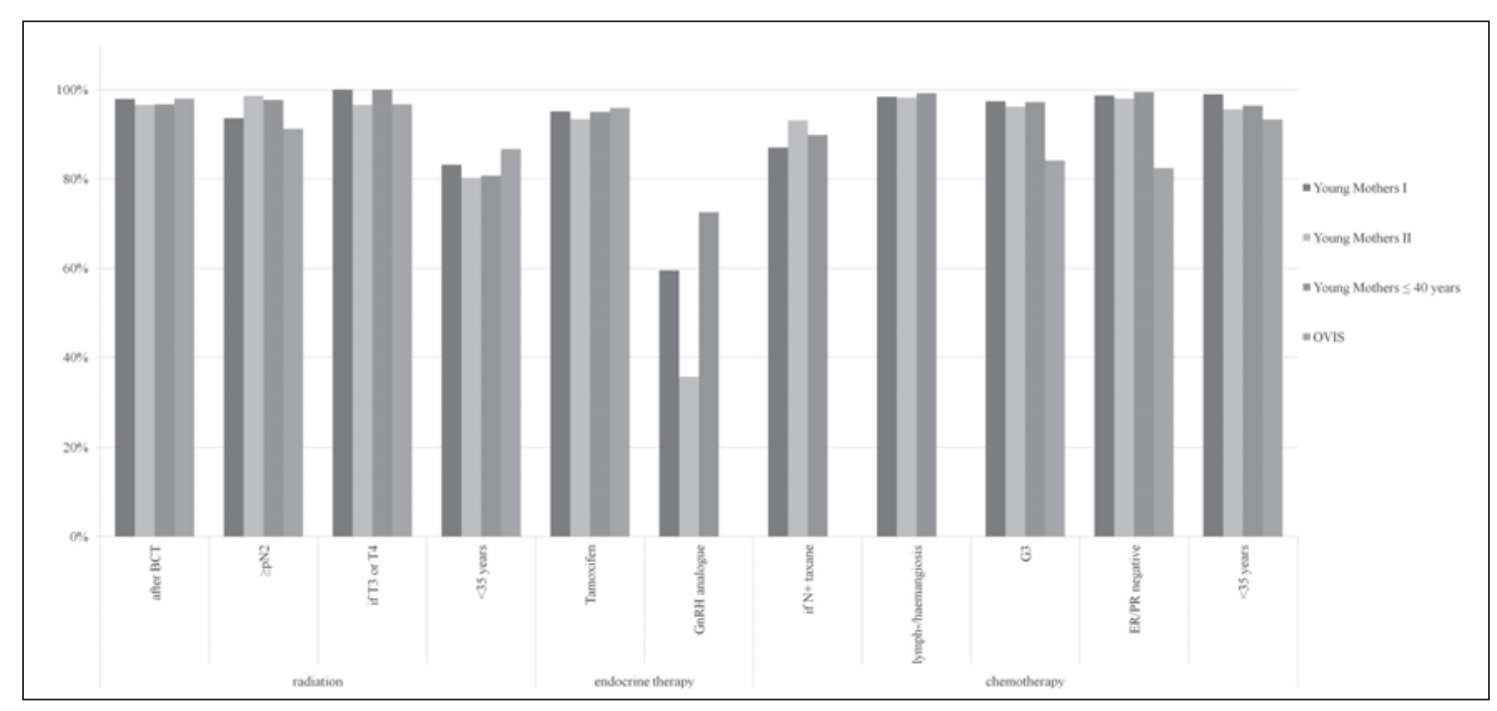


Table 2. Therapy of the cohorts of young mothers (Young mothers I/II and all Young mothers $\leq 40 />40$ years) compared to the OVIS cohort (age-heterogeneous, grouped as 40/> 40 years)

\begin{tabular}{|c|c|c|c|c|c|c|}
\hline & $\begin{array}{l}\text { Young mothers } \\
\text { I }\end{array}$ & $\begin{array}{l}\text { Young mothers } \\
\text { II }\end{array}$ & Young mo & & OVIS & \\
\hline \multirow[t]{2}{*}{ Time period } & \multirow[t]{2}{*}{ 2002-2006 } & \multirow[t]{2}{*}{ 2008-2011 } & \multicolumn{2}{|l|}{ 2002-2011 } & \multicolumn{2}{|l|}{ 2001-2004 } \\
\hline & & & $\leq 40$ years & $>40$ years & $\leq 40$ years & $>40$ years \\
\hline $\mathrm{n}$ & 535 & 518 & 615 & 438 & 76 & 1,065 \\
\hline \multicolumn{7}{|l|}{ Breast surgery, \% } \\
\hline Mastectomy & 31.0 & 19.1 & 25.2 & 25.1 & 26.3 & 32.6 \\
\hline Mastectomy with reconstruction & 14.8 & 17.4 & 16.6 & 15.3 & 35.3 & 8.6 \\
\hline Breast-conserving therapy & 53.1 & 62.7 & 57.4 & 58.4 & 73.7 & 67.4 \\
\hline Axillary surgery, \% & 97.6 & 98.6 & 98.7 & 97.3 & 98.7 & 97.7 \\
\hline SLNB only & 24.5 & 47.5 & 32.8 & 40.0 & - & - \\
\hline SLNB + (AD) & 16.8 & 24.7 & 19.2 & 22.8 & - & - \\
\hline AD only & 56.3 & 26.4 & 46.7 & 34.5 & - & - \\
\hline AD when axillary node positive $(\mathrm{N}+)$ & 98.5 & 94.9 & 97.5 & 96.1 & - & - \\
\hline Radiation, \% & 80.6 & 81.7 & 82.0 & 79.9 & 97.4 & 97.3 \\
\hline Chemotherapy, \% & 90.1 & 87.6 & 93.3 & 82.6 & 94.7 & 82.6 \\
\hline $\mathrm{N}+$ & 98.9 & 98.2 & 93.3 & 97.5 & 100.0 & 92.5 \\
\hline with taxane & 87.0 & 93.1 & 89.8 & 89.7 & - & - \\
\hline No & 81.1 & 80.1 & 88.3 & 69.4 & 91.9 & 77.5 \\
\hline with taxane & 34.7 & 53.5 & 53.3 & 32.3 & - & - \\
\hline Endocrine therapy if ER/PR positive, \% & 95.1 & 93.7 & 95.1 & 93.1 & 92.5 & 97.7 \\
\hline Tamoxifen & 87.0 & 88.0 & 91.7 & 82.7 & - & - \\
\hline Aromatase inhibitor & 8.0 & 5.2 & 2.5 & 6.2 & - & - \\
\hline GnRH-analog age $\leq 40$ years & 72.6 & 62.7 & 68.3 & - & - & - \\
\hline GnRH-analog age $>40$ years & 36.6 & 11.4 & - & 22.1 & - & - \\
\hline Trastuzumab if HER2 positive, \% & 97.4 & 97.2 & 98.6 & 94.9 & - & - \\
\hline
\end{tabular}

SLNB = sentinel lymph node biopsy, AD = axillary dissection, $\mathrm{N}+$ = node positive, $\mathrm{GnRH}=$ gonadotropin-releasing hormone.

special interest because of young age and their role in society, scientific literature on young BC patients is sparse.

In this study we analyzed a specific group of young patients, characterizing their $\mathrm{BC}$ treatment and evaluating the guideline conformity of their treatment. Young patients with $\mathrm{BC}$ have a worse prognosis $[13,14]$ than older women, and the risk for recurrence is also higher [15]. Therefore, the treating physician has to weigh the benefits of therapy against the potential harms, keeping in mind the goal of maximum long-term benefit with minimum long-term toxicity. Therapy in accordance with the guidelines improves RS and OS [2, 9, 10], and should therefore be performed if possible. As presented at the Combating Breast Cancer Conference 2013, a continuous reduction of mortality in breast cancer has been observed over the past few years in Germany. Between 1998 and 2011, the patients of $35-40$ years showed the highest reduction in mortality (39\%) $[13,16]$. This could be associated with the high adherence to the guidelines in the treatment for that young group.

\section{Surgery and Radiation}

After the publication of new findings, the AGO guidelines were changed to include SLNB in 2006 [7]. This resulted in a change in therapy strategies between the cohorts of the young mothers. In cohort I, AD was the standard method; for cohort
II, SLNB had become standard in clinically node-negative (cN0) disease (see table 2). Our results indicate the speed with which new recommendations can be implemented in BC therapy in Germany. Recently, the ACOSOG Z0011 trial showed for patients with $\mathrm{BCT}$ that $\mathrm{AD}$ in $\mathrm{cN} 0$ patients with positive SLNB has no effect on OS, RS or loco-regional risk of recurrence [17] after adequate radiation and systemic therapy. With regard to axillary staging, the AGO recommendations were revised in 2013 with AD no longer being mandatory in those cases [7]. To what extent this change will affect actual treatment practice remains to be seen.

Radiation is recommended after BCT, 3 or more axillary lymph node metastases ( $\geq \mathrm{pN} 2)$ and T3/T4 tumors [7]. In the young mother cohorts we found high adherence to the guidelines (95.7-100\%). Taking age into account as an independent risk factor, there was lower consistency with respect to radiation treatment: $83.2 \%$ in cohort I, $80.2 \%$ in cohort II and $86.7 \%$ in the OVIS group. It seems that this recommendation is not followed as often as the other recommendations.

\section{Chemotherapy}

A high percentage of patients in the cohorts I and II received chemotherapy (between 87.9 and $90.5 \%$ ). A possible explanation could be that young age is regarded as an inde- 
pendent risk factor for recurrence of $\mathrm{BC}$ [18], and that clinicians consider more aggressive treatment for young $\mathrm{BC}$ patients as many studies have reported that young age at diagnosis is a predictor of poor survival [19]. This is consistent with our data in which patients younger than 35 years nearly always received chemotherapy $(97.4 \%$ in the cohort of young mothers, $93.3 \%$ in the OVIS cohort). In node-positive cases, a taxane-based chemotherapy is strongly recommended [7]. In our study, $89.8 \%$ of the patients with node-positive BC received taxane, showing a high guideline adherence. Lymphangiosis or hemangiosis are also predictors for a poor outcome [20], so that these patients should also be given chemotherapy [7]. All young mothers with hemangiosis and $98.3 \%$ of those with lymphangiosis received chemotherapy; again showing high guideline conformity.

A poorly differentiated tumor is generally more aggressive and at risk for occurrence of metastases [21]. In the cohorts of young mothers, $96.8 \%$ with G3 tumors were treated with chemotherapy compared to only $84.1 \%$ in the age-heterogeneous OVIS cohort. Previous studies identified advanced age as the main cause for deviations from guideline recommendations [22]. Reasons include the desire to avoid side effects in patients with co-morbidities, or refusal by patients to trade a reduced quality of life for increased life expectancy [23]. Young patients, besides the BC, are usually healthy. Therefore, they can in general be treated in accordance with guidelines. However, the guidelines do not take cardiac, nephrological or hepatic diseases into account, which may affect the decision for or against chemotherapy.

\section{Endocrine Therapy}

In hormone receptor-positive cases, tamoxifen is approved for premenopausal women to reduce recurrence rate and mortality in adjuvant therapy [24]. Of the hormone receptorpositive patients, $94.4 \%$ in the cohorts of young mothers received endocrine therapy ( $88.5 \%$ receiving tamoxifen) and $97.3 \%$ in the OVIS cohort, showing a high level of guideline conformity in both groups. In contrast, there is no conformity regarding treatment recommendations for $\mathrm{GnRH}$ analogue therapy [25]. In the young mothers I group, of the patients $<40$ years, $72.6 \%$, and of those of $\geq 40$ years $36.6 \%$, received $\mathrm{GnRH}$ analogue treatment. In the young mother II group, $62.7 \%$ of those $<40$ years, and $11.4 \%$ of those of $\geq 40$ years received $\mathrm{GnRH}$ analogue treatment. Altogether the use of $\mathrm{GnRH}$ analogue is decreasing, primarily in patients older than 40 years. This is consistent with current guidelines in which the general use of GnRH analogues in premenopausal women is no longer recommended.

\section{Herceptin}

Expression of human epidermal growth factor receptor 2 (HER2) is an independent risk factor for reduced time to recurrence and OS if patients are untreated [26]. In 2006, the monoclonal antibody trastuzumab was approved for not-metastasized BC with overexpression of HER2/neu. $22.9 \%$ of the young mothers' groups had HER2/neu-positive BC, and $97.3 \%$ of those were treated with trastuzumab, which shows a high level of guideline conformity.

\section{Conclusion}

Our study indicates that young mothers with BC in Germany constitute a special group of patients with certain tumor characteristics. This retrospective analysis demonstrates a high level of adherence to the current guidelines.

\section{Acknowledgments}

We thank 'Klinik Ostseedeich' in Groemitz and especially the patients for their cooperation.

\section{Disclosure Statement}

We declare that we have no conflict of interest.

\section{References}

1 Robert-Koch-Institut und GEKID (Hrsg): Krebs in Deutschland 2009/2010, KID, 2013: http://www. krebsdaten.de/Krebs/DE/Content/Publikationen/ Krebs_in_Deutschland/kid_2013/krebs_in_ deutschland_2013.html.

2 Varga D, Wischnewsky M, Atassi Z, et al.: Does guideline-adherent therapy improve the outcome for early-onset breast cancer patients? Oncology 2010;78:189-195.

3 Banz-Jansen C, Heinrichs A, Hedderich M, et al.: Are there changes in characteristics and therapy of young patients with early-onset breast cancer in Germany over the last decade? Arch Gynecol Obstet 2013;288:379-383.
4 Goldhirsch A, Glick JH, Gelber RD, et al.: Meeting highlights: International Consensus Panel on the Treatment of Primary Breast Cancer. Seventh International Conference on Adjuvant Therapy of Primary Breast Cancer. J Clin Oncol 2001;19:38173827.

5 Field MJ, Lohr KN (eds): Institute of Medicine. Clinical Practice Guidelines: Directions for a New Program. Washington, DC, National Academy Press, 1990, p. 38.

6 Wolters R, Regierer AC, Schwentner L, et al.: A comparison of international breast cancer guidelines - do the national guidelines differ in treatment recommendations? Eur J Cancer 2012;13: $1-11$.
7 AGO.de: http://www.ago-online.de/de/fuermediziner/leitlinienempfehlungen/mamma/.

8 Cardoso F, Loibl S, Pagani O, et al.: The European Society of Breast Cancer Specialists recommendations for the management of young women with breast cancer. Eur J Cancer. 2012;48:3355-3377.

9 Wöckel A, Kurzeder C, Geyer V, et al.: Effects of guideline adherence in primary breast cancer - a 5-year multi-center cohort study of 3976 patients. Breast 2010;19:120-127.

10 Schwentner L, Wöckel A, König J, et al.: Adherence to treatment guidelines and survival in triplenegative breast cancer: A retrospective multi-center cohort study with 9156 patients. BMC Cancer 2013;13:487. 
11 Pritzkuleit R, Waldmann A, Raspe H, Katalinic A: The population-based oncological health care study OVIS - recruitment of the patients and analysis of the non-participants. BMC Cancer 2008;8 311.

12 Waldmann A, Pritzkuleit R, Raspe H, Katalinic A Guideline-compatible treatment of breast cance patients: The status quo in schleswig-holstein. Dtsch Arztebl Int 2008;105:337-343.

13 Eisemann N, Waldmann A, Katalinic A: Epidemiologie des Brustkrebs - Aktuelle Zahlen und Trends. Geburtshilfe Frauenheilkd 2013;73:130 135.

14 Chung M, Chang HR, Bland KI, Wanebo HJ Younger women with breast carcinoma have a poorer prognosis than older women. Cancer 1996; 77:97-103.

15 Kurtz JM, Jacquemier J, Amalric R, et al.: Why are local recurrences after breast-conserving therapy more frequent in younger patients? J Clin Oncol 1990;8:591-598.

16 Würstlein R, Liedtke C: Kongressbericht. Combating Breast Cancer 2013: Chance auf Heilung. Geburtshilfe Frauenheilkd 2013;73:1178-1180.
17 Giuliano AE, Hunt KK, Ballman KV, et al.: Axillary dissection vs no axillary dissection in women with invasive breast cancer and sentinel node metastasis: A randomized clinical trial. JAMA 2011;305:569-575.

18 Han W, Kim SW, Park IA, et al.: Young age: an independent risk factor for disease-free survival in women with operable breast cancer. BMC Cancer 2004;4:82.

19 El-Saghir NS, Seoud M, Khalil MK, et al.: Effects of young age at presentation on survival in breast cancer. BMC Cancer 2006; 6:194.

20 Pinder SE, Ellis IO, Galea M, et al.: Pathological prognostic factors in breast cancer. III. Vascular invasion: Relationship with recurrence and survival in a large study with long-term follow-up. Histopathology 1994;24:41-47.

21 Bloom HJG, Richardson WW: Histological grading and prognosis in breast cancer - A study of 1409 cases of which 359 have been followed for 15 years. Br J Cancer 1957;11:359-377.

22 Séroussi B, Laouénan C, Gligorov J, et al.: Which breast cancer decisions remain non-compliant with guidelines despite the use of computerised decision support? Br J Cancer. 2013;109:1147-1156.
23 Hurria A, Leung D, Trainor K, et al.: Factors influencing treatment patterns of breast cancer patients age 75 and older. Crit Rev Oncol Hematol 2003 46:121-126.

24 Davies C, Godwin J, Gray R, et al.: Early Breast Cancer Trialists' Collaborative Group (EBCTCG) Relevance of breast cancer hormone receptors and other factors to the efficacy of adjuvant tamoxifen: Patient-level meta-analysis of randomised trials. Lancet 2011;378:771-784.

25 Goldhirsch A, Winer EP, Coates AS, et al.: Personalizing the treatment of women with early breast cancer: Highlights of the St Gallen International Expert Consensus on the Primary Therapy of Early Breast Cancer 2013. Ann Oncol 2013;24:22062223.

26 Tandon AK, Clark GM, Chamness GC, et al.: HER-2/neu oncogene protein and prognosis in breast cancer. J Clin Oncol 1989;7:1120-1128. 